\title{
EL APODO EN VILLACAÑAS (TOLEDO): HISTORIAS DE UN PUEBLO
}

\author{
$M^{\mathrm{a}}$ ÁNGEles García ARANDA \\ (Universidad Complutense de Madrid)
}

Por el camino, Dupont y el vagabundo se encontraron con un raro sujeto de luenga barba blanca y negra viserilla de hule, que les saludó muy ceremoniosamente:

- ¿Buscar ustedes tesoros?

- No, señor, nosotros no ¿Y usted?

- No, yo tampoco. Yo soy más modesto. Yo busco apodos, reúno apodos. Yo no me meto con nadie

Dupont quiso decir una frase amable.

- Sí, en seguida se echa de ver que es usted un hombre de bien (Ccla, 1966: 130).

The nickname, word that designates by another term to any person, it is a linguistic phenomenon practically nonexistent in written texts. Our main objective is to show first one approach to his study, for this we will talk about questions of terminology, his tradition along the time, his main characteristics, his formations and tendencies, his popular origin, his use in the literature and, finally, about his presence in Villacañas (Toledo).

\section{Terminología}

Según el Diccionario de la Real Academia apodo es el 'nombre que suele darse a una persona, tomado de sus defectos corporales o de alguna otra circunstancia' y mote es el 'sobrenombre que se da a una persona por una cualidad o condición suya, apodo' (RAE, 1992)'; definiciones que, desde nuestro punto de vista, aluden

\footnotetext{
'Todas las deliniciones que aparecen en estas páginas, salvo que indiquemos otra bibliografía, provienen de esta obra.
} 
a un mismo fenómeno, por lo que serán consideradas sinónimas a lo largo de nuestro trabajo.

María Moliner, a pesar de las alusiones de carácter sociolingüístico que realiza, cree en la sinonimia de ambos términos a juzgar por las definiciones que nos proporciona: apodo «sobrenombre aplicado a veces a una persona, entre gente ordinaria, y muy frecuentemente en los pueblos, donde se transmite de padres a hijos. Mote», y mote «sobrenombre, generalmente alusivo a alguna cualidad, semejanza o circunstancia de la persona a quien se plica por el que se conoce a esa persona. Especialmente los usados en los pueblos, que pasan de padres a hijos y, generalmente, no son tomados como ofensivos. Apodo» (M. Moliner, 1998).

En cambio, Miguel A. Rebollo Torío (1988: 345) considera, partiendo de las deliniciones académicas, que ambos son términos sinónimos, si bien argumenta sin demasiada fïmeza que «parece fuera de duda que tiene más justificación aludir a apodo por más que consideremos la sinonimia en mote», lo cual demuestra los problemas que el autor encuentra al intentar diferenciar con nitidez ambos términos.

Por su parte, Antonio M. Bonachera Cano, de nuevo con el DRAE como punto de referencia sostiene que «la esencia fundamental de los apodos cs un defecto lísico que caracteriza a la persona, mientras que el mote está basado esencialmente en cualquier tipo de cualidad de la persona [...] Ya tenemos aquí, por tanto, la pequeña pero importante matización que nos va a ayudar a distinguir el uno del otro» (Bonachera Cano, 1997: 141-146). Ahora bien, la distinción que propone este autor está hecha sin tener en cuenta que el artículo de mote remite directamente a apodo, climinando así la matización de la que parte Bonachera Cano. Por otro lado, cl autor parece obviar la amplitud semántica de las dos definiciones, pues cuando la Academia utiliza «o de alguna otra circunstancia» (apodo) y «cualidad o condición suya» (mote), manifiesta la clara dificultad en la delimitación del contenido de estos dos conceptos.

Frente a los autores que defienden la sinonimia de ambas voces y frente a los que postulan su distinción sin demasiada solidez, Luis A. Gómez Marcker y Manticl Seco, Olimpia Andrés y Gabino Ramos son partidarios de la distancia cxistente entre ambos términos de acuerdo con criterios personales y, por tanto, subjetivos. Para Luis A. Gómez Marcker el apodo es un «nombre que se da a una persona considerando sus defectos físicos, síquicos o alguna otra circunstancia. Generalmente implica menosprecio, ironía o burla, razón por la cual se suele hablar del apodo como de un mal nombre» (Gómez Macker, 1977: 104). Si bien el autor parte de la delinición académica, le proporciona a la voz una connolación peyorativa que objetivamente no posee. En el otro extremo, y también atendiendo a critcrios particulares, se encuentran Manuel Seco y sus colaboradores alïrman que el apodo «es un nombre frecuentemente de origen calificador o humorístico que 
coloquialmente se da a una persona en lugar del suyo propio o a veces añadido a él», micntras que el mote «es un apodo, frecuentemente de carácter despectivo» (M. Seco - O. Andrés y G. Ramos, 1999).

Antc lal situación, una conclusión se impone: la indeterminación de la definición académica -de la que casi todos los especialistas parten- provoca o bien la adopción de un término en detrimento de otro sin un criterio justificado demasiado claro, o bien la asignación de matices a estos términos en función de la propia intuición o experiencia del autor.

Por rodo ello, lo único que puede afirmarse con cierta seguridad es que la función de estas voces es la de designar a través de otro término, giro u oración a cualquicr persona que posea un rasgo especialmente significativo, de modo que el nacimiento de la nueva alusión refiera única y exclusivamente a un ser sin lugar a cquívocos. Si ésta es original y tiene una buena acogida en la comunidad se irá, probablemente, heredando de padres a hijos, de tal forma que en muchas ocasiones se perderá todo rastro del origen de ese apodo, encontrándonos hoy motes que no podemos descifrar.

En ocasiones, encontramos otros términos como alcurnia, alias, pseudónimo o sobrenombre en perfecta sinonimia con los dos anteriores. Una rápida consulta a cualquicr diccionario de la lengua española nos permite deshacerla y ver con claridad que los rasgos esenciales que caracterizan a estas voces difieren notablemente de los anteriores. Tan sólo podría ser significativo el caso de sobrenombre, que según el DRAE es el «1. Nombre que se añade a veces al apellido para distinguir a dos personas que tienen el mismo. 2. Nombre calificativo con que se distinguc especialmente a una persona»; es, pues, el término más extenso y con más amplitud y por tanto el que mantiene una relación de hipcronimia con respecto a los demás. De acuerdo con lo dicho hasta aquí, podemos alirmar que si bien «todo apodo es un sobrenombre, no todo sobrenombre es forzosamente un apodo» (Rebollo Torío, 1988: 345), por lo que la sinonimia, en este caso, ha de ser tratada con cierto cuidado.

Estas consideraciones justifican el uso indistinto que en este trabajo hacemos de las voces sobrenombre, apodo y mote.

\section{Tradición}

Ya en la Antiguiedad latina podemos encontrar los primeros ejemplos de apodos o motes. Recordemos que la forma del nombre latino era: praenomen, nomen y cognomen; con el primero se aludía al nombre propio de la persona, el segundo designaba lo que hoy es el apellido, es decir era el nombre de la gens (el linaje, la 
estirpe, la lamilia) y finalmente, el tercero era el que correspondía a un sobrenombre individual.

Así por ejemplo, Publius Cornelius Scipio (el) Africanus Major, tenía por nombre Publius Cornelius, el de la gens de su familia era Scipio, y su sobrenombre (el) Africanus Major, debido al gran número de campañas que llevó a cabo en las ticras africanas, y Major, porque hubo un descendiente que siguió sus pasos en materia bélica, Publius Cornelius Scipio (el) Africanus Minor. Otro caso signilicativo lo representa Marcus Aurelius Caracalla, que sigue el esquema anterior, aunque esta vez el sobrenombre atiende al reparto que hizo entre la plebe de un gran número de caracallas (túnicas ajustadas al cuerpo que tenían mangas y capuchas). También había ejemplos de sobrenombres procedentes del lugar de origen: Junius Juvenalis Aquinate (de Aquino), o Publius Vergilius Maro (de Maronca).

Esta costumbre pasó a las lenguas románicas, de modo que hoy conservamos los motes o apodos con los que se han hecho ${ }^{2}$ famosos algunos de nuestros más destacados personajes: Alfonso X el Sabio, Pedro I el Cruel, Jaime I el Conquistador, Fernando e Isabel los Reyes Católicos, Luis XIV el Rey Sol, Domenikos Theotokopulos el Greco, Miguel de Cervantes el Manco de Lepanto, Fernando Valenzuela el Duende de Palacio....

Tendencia que se ha perpetuado, llegando a la actualidad y dando como resultado un sinlín de apodos en cualquier campo de la vida: Manuel Díaz el Cordobés, Vicente Ruiz el Soro ${ }^{3}$, Diego Armando Maradona el Pelusa, Alfredo Di Stélano la Saeta Rubia, Diana de Gales la Princesa del Pueblo, Félix Rodríguez de la Fuente el Amigo de los animales, Bruce Springten the Boss, Elvis Presley el Rey, Mike Jagger Morritos, Juan Pablo I el Papa viajero... Apodos, éstos, mucho más transparentes en su origen, debido a la cercanía y popularidad de sus personajes.

No sólo han sido objeto del apodo los personajes famosos, sino también, como puede imaginarse, el pueblo llano, sólo que, es obvio, los apodos populares son conocidos por una comunidad mucho menor, están más restringidos en su distribución social y geográfica.

\footnotetext{
${ }^{2}$ Muchos de estos apodos se han consolidado con el paso del tiempo o incluso en la actualidad más inmediata, sin embargo, otros muchos ya fueron conocidos así en su momento; véase al respecto $\mathrm{M}$. Chevalier, 1982: 61-77.

${ }^{3}$ Para Miguel A. Rebollo Torío el hecho de que no haya torero sin apodo, pero sí que haya rejoneadores sin él tiene, probablemente, una explicación social: los orígenes modestos del primero, frente al buen acomodo del segundo, que ha de posecr cierto número de caballos - con lo que esto conlleva- para poder desarrollar así su trabajo.
} 


\section{El apodo y la onomástica}

El apodo o mote es alusión obligada a la hora de tratar el tema del origen de nombres propios y apellidos; si bien, hoy en la mayoría de los casos, se ha perdido el sentido originario de éstos, en todos ellos subyace un elemento que pretendía evocar o aludir a un determinado rasgo, ya fuera físico o moral, de la persona o cosa a la que se asignaban.

El nombre propio tiene en su significado un mensaje desde tiempos e idiomas a menudo ya desaparecidos de la memoria de las personas. $\mathrm{Al}$ principio (y aún hoy en algunas culturas), designaba siempre alguna cualidad, imaginaria o real, que se suponía o deseaba que el recién nacido poseyera. Generación tras generación acaban cayendo $\mathrm{en} \mathrm{el} \mathrm{ámbito} \mathrm{de} \mathrm{la} \mathrm{rutina,} \mathrm{fosilizándose} \mathrm{y} \mathrm{perdiendo} \mathrm{su} \mathrm{inicial} \mathrm{valor}$ cvocador.

El caso de los apellidos no es menos productivo. Algunos estudios acerca de la onomástica española muestran con cierta claridad que el origen de ciertos apellidos españoles hay que buscarlo en antiguos motes o apodos (García Gallarín, 1999). Por otro lado, tenemos constancia de que en los primeros siglos de la Edad Media (Salazar y Acha, 1991; Codera, 1909: 323-334) se produce un empobrecimiento onomástico que se va extendiendo entre el pueblo, al repetirse con demasiada frecuencia los mismos nombres imitando a las clases altas; este hecho provoca la creación de un nucvo sistema de diferenciación, que se produce a través de un sobrenombre, cl cual en la gran mayoría de los casos obedecía al oficio ejercido por el cabcza de familia, a alguna característica descollante o al lugar de su residencia o de su origen familiar. Tendencias que se han ido conservando con el paso del tiempo y que veremos ejemplificadas en el caso de Villacañas ${ }^{4}$, pues ha pervivido cl mote como marca diferenciadora en una comunidad; las distintas formas, los diferentes orígenes, la formación en sí... han variado algo, pero la esencia sigue siendo la misma, aún perdura.

Este breve recorrido por la historia onomástica se convierte pronto en un argumento de peso a favor de la importancia e influencia del apodo, que se traduce en la necesidad de un estudio exhaustivo de un fenómeno que alcanza tales dimensiones.

\footnotetext{
"Villacañas cstí situado en el sureste de la provincia de Toledo. Su principal dedicación ha venido siendo traklicionalmente la agricultura, si bien en las últimas décadas se observa un gran crecimiento gracias a la incorporación de grandes industrias dedicadas a la fabricación de puertas, lo cual ha provocado un aumento considerable del número de vecinos, que en la actualidad alcanza los casi 10.000 habitantes.
} 


\section{Características}

El apodo es un fenómeno de amplia extensión en nuestra lengua, cumpliendo una función básica que lo distingue: sirve para identificar a las personas; aunque cabe completar esta primera caracterización con otros rasgos que lo definen.

1) La suposición de la que hay que partir a la hora de estudiar el apodo, apuntada por la profesora Olga Mori (1993: 101), es que «el apodo es un signo lingüístico motivado, identificador y evocador». El primer rasgo que caracteriza a los apodos cs, pues, su clara motivación.

2) El apodo cumple un importante rol sociocultural, pues establece vínculos especiales cntre las personas que los poseen y las que los usan. Así, y de acuerdo con W. Beinhauer (1991), uno de los rasgos del mote o apodo es que su «sentido sólo puede ser entendido por los iniciados, conocedores o sabedores de la situación a que el sobrenombre debe su origen». Así, a medida que aumenta el uso del apodo, la familiaridad se va haciendo más estrecha, de modo que actúa como vínculo de unión entre los interlocutores, consiguiendo una total complicidad. Tanto si usan el apodo entre ellos, como si lo usan referido a una tercera persona, el efecto es el mismo, de modo que «cuanto más fuerte sea la convivencia, cuanto más estrechas sean las rclaciones sociales, cuanto más densas sean las redes sociales existentes en ella, mayor originalidad y mayor número de apodos y motes existirán» (Bonachera, 1997: 141).

3) Por otro lado, el apodo trata de identificar con un nombre distinto al de pila a una persona determinada, con la intención no sólo de designar sino también de evocar lo que sirvió de motivo creador; de ahí que se hable de la transparencia del mote, frente a la opacidad del nombre propio ${ }^{5}$.

4) En su afán de identificar y designar inequívocamente a alguien, el apodo suele proceder de un destacado aspecto físico o moral, de una anécdota, de una prolesión poco abundante,... que alguien anónimo impone a otro, extendiéndose al resto de la comunidad; diferenciándose así del nombre de pila, pues éste está impuesto por la lamilia con el objeto de identificar a la persona; la autoría del apodo, en cambio, es más difícil de establecer.

5) No es un fenómeno universal, ya que no todos poseemos apodo, pero es enormemente firecuente.

6) De acuerdo con su categoría gramatical, se puede decir que el apodo constiluye una forma «a caballo entre el nombre común y el propio» (Ariza, 1993: 40). Siguiendo los criterios que definen al nombre propio y sus diferencias con el nombre común que propone Manuel Ariza, el apodo comparte con el nombre común la flexión genérica pero no la de número, ya que no suele admitir —al igual

${ }^{5}$ Para todo esto véase cl artículo de Miguel A. Rebollo Torío, anteriormente citado. 
que cl nombre propio- el plural, los casos como los Guillenes no son considerados plural sino que son «aplicados a una pluralidad de miembros de una familia» (Ariza, 1993: 36).

Del mismo modo, $\mathrm{M}^{\mathrm{a}}$ Jesús Fernández Leborans admite en su presentación de las características y funciones del nombre propio que si bien «no hay unanimidad de critcrio respecto a lá relación entre el nombre propio y el número gramatical», sí que parece evidente que el shecho de que los NNPP puedan aplicarse a una pluralidad de objetos no significa que el nombre propio pueda tener «semánticamente» plural [...] Efectivamente, la referencia de 'unicidad' que distingue el NP del NC es consecuente con esta consideración» (Fernández Leboráns, 1999: 86), de manera que «apodos y pseudónimos constituyen un modo sccundario de designación propia» (Fernández Leboráns, 1999: 81).

Desde el punto de vista semántico, comparte de nuevo con el nombre propio su propósito de singularización e identilicación de la persona a la que aluden; ahora bien, micntras que tal y como defiende Manuel Ariza en el caso del nombre propio «no importa su significado léxico [...] tenemos una clase de nombres, los apodos, en los que en numerosas ocasiones se conserva su significado [...]. Se dice que son auténticos nombres propios cuando han perdido su significado, es decir, si el hijo de Enrique el Cojo ya no cs cojo» (Ariza, 1993: 40), todo lo cual justificaría su cstadio intermedio entre el nombre propio y el común.

7) Es un fenómeno más extendido en el campo que en la ciudad. Tal hecho se debe probabiemente, a las estrechas relaciones que se mantienen en los pueblos, frente a la distancia que entre los individuos impera de las ciudades. Esta circunstancia cstá motivada únicamente por un hecho evidente: el tamaño de la población; mientras que en la ciudad el gran número de habitantes hace que una persona se relacione sólo con un reducido grupo (con el que por diferentes motivos más contacto mantiene), en un pueblo cualquier tipo de relación (laboral, de estudios, comereial...) provoca que sean siempre los mismos individuos los que forman parte de clla. Por otro lado, las familias o grupos familiares son menos en los pueblos, por lo que los apellidos (y los nombres + apellidos) se repiten, perdiendo el valor identificativo, individualizador que deberían tener.

8) Si se aticnde a un punto de vista de estratos sociales, encontramos que cl apodo es prácticamente inexistente entre las clases altas (salvo si se posee una gran trascendencia social o histórica), mientras que los grupos marginales y el pueblo llano acuden a él frecuentemente.

9) En la forma del apodo hay una gran variedad de soluciones: vulgarismos fonéticos y morfológicos, onomatopeyas, metátesis, extranjerismos, cultismos... En cuanto a la estructura interna va desde un elemento simple hasta toda una oración.

10) La vida del apodo puede ser temporal, muriendo con el individuo que lo origino, o duradera, cxtendiéndose a los descendientes del individuo en cuestión; es 
en este caso cuando el apodo pierde con mayor facilidad la motivación que poseía en su origen.

11) Suele aludirse también en una caracterización del apodo a la diferencia que éste establece entre hombres y mujeres; al parecer las mujeres reciben apodos en mucha menor medida, y éstos suelen referir a cuestiones como la belleza, la maternidad o el matrimonio.

12) Por último, se puede observar cómo la persecución de la ironía, el humor y la gracia acompañan a un gran número de apodos.

13) La extensión del apodo es variable, o bien puede actuar en un conjunto importante de gentes - por lo general familias o pueblos enteros ${ }^{6}$ o bien individualizarse en personajes concretos.

La exposición de las características propias del apodo o mote nos permite justificar los orígenes populares de este fenómeno, su vigencia actual, su relación con otros nombres, su creatividad y, sobre todo, la necesidad de plasmar todas estas afirmaciones en un corpus real.

\section{EI apodo: creación popular}

Dos son los argumentos que utilizaremos aquí para justificar el origen popular de este fenómeno.

Por un lado, el tipo de lenguaje en el que aparece ya que en ningún lenguaje escrito u oral que tenga cierto carácter formal, aparece el apodo (véanse casos como el lenguaje científico, técnico, jurídico...). Una clara manifestación de ello puede apreciarse en el diferente tratamiento que se da al mismo objeto en los bandos callejeros matrimoniales y en las amonestaciones eclesiásticas. En los primeros es muy frecuente la identificación de las personas que van a contraer matrimonio, a través de sus respectivos apodos o el de sus familias ${ }^{7}$, mientras que la amonestación eclesiástica se caracteriza por su rigurosa formalidad. Ello nos lleva, de nuevo, al argumento del origen popular del fenómeno.

Por otro lado, se produce el paralelismo don, doña ausencia de apodolausencia de don, doña presencia de apodo. Así, en el caso de Villacañas,

\footnotetext{
"Dentro de los cuales estarian, entre otros, los apodos que corresponden a las distintas poblaciones; es el caso, en España, de apodos como: los gatos (los madrileños), los bolos (los toledanos), los boquerones (malagueños),... o los ejemplos existentes de apodos entre pueblos vecinos y rivales: los charnegos (inmigrantes en Cataluña), escoltis (catalanes),... casos de los que presentan numerosos ejemplos $\mathrm{G}$. García Vergara (947 y 1950) y J. Ocaña Torrejón (1961).

${ }^{7}$ En Villacañas, suele ser un pliego de papel que los amigos de la pareja que va a contracr matrimonio colocan por las calles del pueblo, en el cual se anuncia de manera informal la celebración, motivo por el que suelen aparecer apodos, fenómenos de la lengua coloquial, alguna anécdota curiosa, fotogralías ingeniosas...
} 
se habla de don José Crespo o don Juan Villarreal (que son médicos del pueblo); don Gerardo (cl párroco); don Luis (que si bien recibe distintos apodos por ser uno de los maestros del pueblo, éstos son temporales porque dependen de las diferentes generaciones de alumnos). En cambio, las clases sociales menos pudientes carecen de tratamiento, y el apodo se convierte en signo identificativo. Ello es muestra a la vez de unas relaciones sociales fuertemente jerarquizadas, aunque tienden a desaparecer con el cambio de estructuras sociales que estamos viviendo.

Una manifestación muy evidente de la relación establecida anteriormente entre clases sociales/posesión de apodo, es la que presentaba hace varias décadas la designación de la gente más pobre y desfavorecida en Villacañas: se les conocía como «los de por allí arriba». En la configuración urbana del pueblo, las personas con un nivel socio-económico medio y alto se situaban en el centro y proximidades, mientras que en las afueras, cerca ya del inicio de la Sierra, habitaban los de un nivel bajo. Es decir, en nuestro lugar de estudio se mantenía un apodo para toda la clase baja desde un punto de vista económico, mientras que los de clase más elevada se caracterizaban de nuevo por la ausencia de éste.

Todo cllo prueba que cl apodo es de origen popular, arraigado sobre todo en el pueblo, quicn actúa de propagador del fenómeno; de ahí su presencia masiva en el ámbito rural y su escasez en cl urbano, y de ahí también la diferencia que a partir de él se puede establecer entre las diferentes clases sociales de una población concreta.

\section{El apodo en la literatura}

El apodo presenta unos orígenes populares, no sujetos rígidamente a los cánones gramaticales, de ahí su importante vitalidad; pero ésta no está presente sólo en la lengua oral de los medios rurales, sino que es también muy frecuente cn la lengua escrita, tanto de lipo 'semiliterario', como los carteles de corridas de toros o las esquelas", como de tipo literario, propiamente dicho.

Y así cncontramos en el ámbito de la literatura numerosos ejemplos de utilización del apodo, como (Rebollo Torío, 1988: 343) «Se llama Manuel Alonso Bernardo, aunque es mucho más conocido entre sus compañeros de profesión -

\footnotetext{
"Este apodo colectivo ha desaparecido en la actualidad, debido tanto a la generalizada mezcla de clases, conno a la expansión geográfica del pueblo hacia la zona alta de las Sierras. Villacañas ha mantenido hasta hace poco la característica distribución por anillos de las zonas rurales; es decir, un núcleo clatramente definido en el que se asientan las clases más acomodadas, y que se corresponde con cl centro del pucblo - iglesia, mercado, ayuntamiento, plaza-, organizándose el resto en torno a él, siempre teniendo en cuenta que a medida que nos alejamos del centro, nos acercamos a las zonas más humildes. "La aparición de motes o apodos en esquelas aparecidas en periódicos de Pamplona, es estudiada con detalle por R. Ollarquina, 1996.
} 
pintor de brocha gorda- por el apodo de Lerele» de J. A. Llamazares; o «A la llegada del conde a Cataluña, los carlistas temían que el Ros de Eroles, el Pep del Oli y el Llarch de Copons, los tres castigados en 1827...» de P. Baroja, no son inlrecuentes en cualquier época de la literatura universal.

El gran macstro del apodo en la literatura española es Miguel Delibes, quien nos ha dejado un valioso corpus de apodos, con las respectivas explicaciones acerca de los origenes de cada uno. Como muestra de ello, baste con cxaminar su obra El camino, en donde la denominación de los personajes se hace siempre partiendo del siguicnte esquema: nombre propio (unas veces con apellido y otras sin él) + coma + apodo. El personaje protagonista de la obra es Daniel el Mochuelo, por la manera de mirar las cosas, alrededor del cual desfilan numerosos personajes del pueblo que además de un papel en la historia poseen un apodo que les es inseparable. Lola Guindilla, por su cara redonda y colorada y su carácter picante y agrio como el aguardientc; Germán el Tiñoso, por sus calvas en la cabeza; Moisés, el Maestro Peón porque torcía la boca; Quino el Manco; las Cacas, cinco hermanas llamadas así porque sus nombres de pila eran Carmen, Camila, Catalina, Casilda y Caridad; Andrés el hombre que de perfil no se ve, etc.

\section{El apodo en Villacañas}

A partir del corpus conseguido en Villacañas ${ }^{10}$, dos son las clasificaciones que se pueden hacer con el material recogido:

I) Clasificación por el origen directo del apodo.

1. Por el lugar de origen. Villacañas, situado en una comarca dedicada tradicionalmente al sector agrícola, sufrió hace unos años un gran desarrollo industrial, lo que provocó la migración de una gran cantidad de gente en busca de trabajo en las incipientes fábricas. De ahí que Villacañas posea algunos apodos que cvoquen cl lugar de origen de esas gentes forasteras: Carmen la Murciana; Antonio el Lillero, (de Lillo, Toledo) o los Moteños, familia procedente de Mota del Cucrvo (Cuenca).

2. Por una anécdota determinada. Es el apartado más numeroso, y si bien dentro de él se incluyen apodos de muy diverso origen, es el epígrafe cargado con más sentido del humor y en el que se aprecia perfectamente la creatividad y

\footnotetext{
${ }^{1 "} \mathrm{El}$ conjunto de apodos recogidos en Villacañas lo forman más de ciento cincuenta sobrenombres; ia parte mís numerosa fue reunida entre diciembre de 1997 hasta, aproximadamente, marzo de 1998, si bien han ido aumentando hasta la actualidad. Por falta de espacio, en este trabajo sólo recojo los más interesantes; para no herir susceptibilidades, cvito en la medida de lo posible, el nombre de pila de los apodades. Por otro lado, queremos manifestar que aquellos casos de apodados que rechazan o reniegan de sus apodos han sido respetados y no incluidos en este trabajo.
} 
peculiaridades que caracterizan a un pueblo. Veamos algunos de ellos: Mengañastes por no cumplir una promesa hecha; Matachivos por matar de niño a un chivo; Francisca Medietes por tener en dos ocasiones mellizos; Dolores Muchachos porque sólo tuvo hijos varones; familia de los Perdios por haberse perdido de niño uno de sus miembros; Corremozas, cuyo origen es claro; Robamelones por hallarle en un melonar robando el fruto que éste había dado; Figu(ra) por destacar jugando al fútbol; Tabernera por la frecuencia con que visitaba las tabernas del pueblo; Culohierro por su insensibilidad aparente al dolor cuando con alguna de sus gamberradas se ganaba un azote; Orejitas porque un cerdo le amputó parte de ellas; Botones por su tozudez al querer un traje con cllos a pesar de la nueva moda; familia de los Tartaneros porque su patriarca llegó al pucblo con tan sólo una tartana; la Refranera porque apostilla toda conversación con un refrán; el thesto la Jícara que perdió la visión en un ojo al romper una jícara de un poste de la luz; o el tío Manillas porque tras la Guerra Civil veía muy difícil volver a dedicarse a su oficio de guarnicionero y no sabía qué podía hacer con sus manos para sacar a su familia adelante.

3. Por una cualidad o rasgo. Un grupo muy importante de apodos es el de acjucllos que cvocan características físicas; es evidente que señalan rasgos muy marcados y sobresalientes de los apodados. Son éstos los apodos más transparentes de la clasificación, veámoslo: el Gordo; el Cojo; los Palosecos por su extremada delgade\%: Huesitos; los Aguja, por ser altos y delgados; la Culona; el Canijo; Chiquitín y Gigan(te) ejemplifican cl caso de las personas que son demasiado altas; Patachicles por sus larguísimas y delgadas piernas; cl Duende por ser pequeñín, inquicto y ágil; el Quemado, porque se quemó la piel de niño y le dejó secuelas; Lupas o Lupillas porque necesita y lleva gafas; Tres Pelos por su calvicie; los Colora(d)os por su color de cara rojizo; Narizón por su nariz prominente; la Chata por su aplastada nariz; Viruta debido a que su rizado pelo semeja los espirales que desprende el hierro o la madera cuando son labrados; Cara Alegre por su sonriente cara; Ia Bizquilla; el Jaro porque es rubio y semeja a la Jara, planta de flores amarillas; el Masca porque mueve la boca constantemente, como si estuviera masticando; la Huelepedos por su cara arisea y lo áspero de su carácter; Intermitencias por un tic lacial que le provoca abrir y cerrar los ojos con frecuenciá el Sota por su parecido físico con la imagen de un paje o inlante que aparece en la carta décima de cada palo de la baraja española; los Chinos dos hermanos que recibicron su sobrenombre por sus rasgos laciales.

Suelen ser éstos los apodos más efímeros, porque si no se hereda la cualidad física, no se hereda el mote, si bien hay ejemplos de herencias de apodos físicos a través de la forma: «el hijo de...».

Los apodos cvocados por rasgos morales revelan el alto grado de observación de los micmbros de una comunidad entre sí. En este corpus, muchas de las 
características personales consideradas reprobables o negativas han servido de motivo para la creación de apodos. Aunque suelen encerrar una crítica o burla, en la mayoría de los casos, la intención principal del creador no es herir sino divertir, causar gracia. Así, tenemos Cilindro o Cilindrada porque es extremadamente bruto; Adoquín por ser tozudo y cabezón; Veleta por su carácter alocado; los Valientes...

4. Por el oficio propio o paterno. Las designaciones de profesiones y oficios se utilizan también para crear apodos. En un pueblo como Villacañas, donde la mayor parte de la población se dedica o a la industria de la madera o a la agricultura, los apodos de oficios o profesiones se reservan para los que se salen de lo común. De este modo, todos los apodos recogidos sobre este particular aluden a profesiones que forman las minorías y que en numerosas ocasiones ya han desaparecido, aunque el mote se mantiene en los descendientes de quienes ejercieron el oficio: Laña por ser lañadores; Sastres; Voltio porque es electricista; Basuras porque es el conductor del camión que recoge y vacía los contenedores de basura; Mistomates porque vendía verduras; Colchonera; Carretero porque se dedicaba a hacer y arreglar carretas; Calero; Herrero; Pecera porque su bisabuelo fue el primero que llegó a Villacañas vendiendo pescado; Curtidor; Esquilador; Garbancero; Tejero; Molineras; Carcelero; Calderera porque vendía calderos; Buta(nero); Tortera; Vacas porque se dedicaba a la cría de ganado vacuno....

5. Por la vestimenta. Son raros los ejemplos en los cuales la vestimenta ha servido de inspiración, hecho que probablemente se deba a que casi todos los habitantes del pueblo se adaptan a las normas de la moda general. Sin embargo, dos son tos ejemplos que se han encontrado en Villacañas con este origen: Mono y Elásticos. El primero alude al traje de faena, de cuerpo y pantalones de una pieza, que dado su color sufrido y su tela fuerte, es utilizado por numerosos obreros, pero que en nuestro caso se individualiza debido al uso abusivo que de éste hace alguien en particular; el segundo, en cambio, alude al tipo de jersey que llevaba el abuelo de la familia.

6. Por el apellido de la familia. En el corpus de apodos recogidos en Villacañas, encontramos también ejemplos de sobrenombres que provienen del apellido familiar. Lo más característico de ellos es el plural y su carácter familiar, pues en ningún caso acompaña a un solo miembro de la familia. Los ejemplos más claros son: los Montes (en donde el propio apellido ya tiene forme plural), los Pachecos (de Pacheco), los Molinas (de Molina), los Sanz o Sanes, las Simonas (Julia y Cándida Simón), los Prous, los Guillenes (de Guillén), los Yébenes o los Lobatos.

7. Por el nombre propio de un familiar relevante. Existen también apodos creados a partir del nombre de un miembro de la familia, que por cualquier hecho adquirió en el pueblo una relevancia social significativa. Tal es el caso de: los 
Tomasones (de Tomás, el Tomasón); las Benitas; la Apolinarcilla (su padre se llamaba Apolinar); los Francisquitas; la Carpa (de Policarpa); los Nicomedes; los Prudencios; los Genarillos; los Merceditas; los Rupertos; los Carmelos; la Felipilla...

8. Los que proceden de un personaje famoso. El vínculo, que a raíz de cualquier motivo, se establece entre un apodado en potencia y un personaje del mundo del arte, de la televisión, de la canción,... favorece la aparición de los apodos de origen 'famoso'. Es obvio que la cronología de este tipo de apodos es muy reciente (sobre todo de los 10 ó 20 últimos años), ya que coincide con la expansión masiva de los medios de comunicación. Los ejemplos en Villacañas no son demasiado abundantes, si bien hay que destacar los siguientes testimonios:

a) Los que se basan en una persona famosa: la Turner tomó este sobrenombre dada su forma de vestir y su cabello despeinado, creando una imagen extremadamente llamativa y de un gran parecido a la de la cantante Tina Turner; Miguel Pasión vistió y se peinó durante algún tiempo al estilo del bailarín Joaquín Cortés, esta época coincidió además con el anuncio en el que Cortés prestaba su figura a la marca de coches Seat, dando a conocer el modelo Seat Ibiza Pasión, lo que originó este sobrenombre; la Thatcher es tal debido a su fuerte carácter y su andar crguido...

b) Los que están basados en personajes del mundo de ficción: Son Goku, ya que su peinado semeja al de éste personaje de dibujos animados; Draculín por sus colmillos sobresalientes; Ia Gallifante porque posee tan poca gracia física como la mascota del programa de televisión Juego de niños, mezcla de un gallo y un clefante.

9. Los que tienen un origen animal. Uno de los motivos básicos que sirven de inspiración al creador del apodo es el parecido, y la base de éste suele hallarse o bien en las realidades más cercanas a su vida cotidiana, o bien en realidades conocidas por un gran número de hablantes. Uno de los puntos de apoyo en la crcación del apodo, en este sentido, es el del parecido con los animales, así son muy frecuentes algunos apodos del tipo: el Pato, por la forma de andar; el Culebra, por ser delgado y escurridizo; el Galgo por su velocidad corriendo; el Conejo, por los dientes sobresalientes; el Loro, por la nariz o por la verborrea; el Pollo, por su pelo peinado en forma de cresta...

Se puede ver que normalmente la base es un parecido físico con el animal en cuestión, éste es o muy conocido por el hablante o muy cercano a él, razón por la que no se suelen encontrar apodos basados en el parecido con animales extraños.

10. Los que tienen un origen vegetal. Como en el caso anterior, otra realidad muy próxima al hombre es la vegetal, de ahí que la existencia de apodos con base vegetal haya dado también algunos ejemplos. Los cuatro casos siguientes observan una clara presencia vegetal: el Lechuga por su afición a comer esta verdura; Patato 
por su dedicación a la siembra y venta de patatas; Patatilla por su pasión por las patatas asadas; Cebollero-Pataquero porque vendía patacas " y ccbollas.

11. Los que aluden a comidas. En este grupo encontramos Gachas, Mojete y Potaje; los dos primeros por su afición desmedida a estos guisos, mientras que cl segundo se lo debe a una mancha en la cara que le hace parecerse al aspecto que adquicre este suculento puchero.

II) Clasificación temporal, es decir apodos que son ancestrales - como Mengañastes, Matachivos, Pisamorena, Manazas, Ocho, Robamelones, Galgo, Orijitas, Maderos, Duende, la Tonta los nublaos, Sifonera, Melón, Maquinero- y apodos que son de creación reciente - como el Sida, Chirla, Pumuki, Trenes, Torrijas-. La primera conclusión que se impone con respecto a la pervivencia del apodo es que éste, como fenómeno, no parece que vaya a morir; ahora bien, el cambio que parce que se está produciendo es la reducción de su extensión en amplias comunidades.

Un estudio exhaustivo de los datos recogidos nos proporciona los siguientes resulados: a) son más numerosos los apodos ancestrales que los de creación reciente. De hecho, si en el cómputo total analizamos éstos últimos, observamos que el grupo creado a partir de personajes famosos ha de ser tratado con cierta cautela, pues no sabemos si se va a perpetuar (si las generaciones futuras no conocen al personaje público en cuestión, ¿mantendrán cl apodo?), y de no ser así se perdería uno de los rasgos esenciales del apodo; b) la conservación de apodos ancestrales verifica que es un fenómeno vivo cuya extensión está variando en los últimos años, ya que aumenta la restricción de los apodos pues éstos son conocidos cada vez cn mayor medida por un menor número de hablantes.

La cscasa valoración por nuestros antepasados, la huida de la vida en cl campo, la imitación de las costumbres urbanas, la influencia de los medios de comunicación, el aprecio por el presente y sobre todo por el futuro son las principales causas de csta situación. El apodo no se va a extinguir, pero es patente cl retroceso que ha sufrido. Esperemos que los desarrollos de los estudios ctnográlicos y antropológicos resuciten en cierta medida una de las tradiciones más emblemáticas de nuestra cultura, de tal modo que entre todos podamos contribuir a la conservación de este magnílico legado.

\footnotetext{
${ }^{11}$ Según el $D R A E$ 'Tubérculo de la raíz de esta planta, que es de color rojizo o amarillento, fusiforme, de seis a siete centimetros de longitud y cuatro o cinco de diámetro por la parte más gruesa, carne acuosa algo aracarada y buen comestible para el ganado'.
} 


\section{Formaciones y tendencias}

El mote o apodo nos proporciona numerosos datos lingüísticos acerca del habla coloquial de una comunidad; su origen popular o la expansión entre las gentes menos cultas de un pueblo verilican este hecho.

La forma de los apodos presenta una gran variedad, que normalmente va unida al grupo al que ćstos pertenecen; por otra parte, puesto que el objetivo que, al parecer, se persigue en la creación de la mayoría de los apodos es festivo, las formaciones son humorísticas o irónicas, de manera que el pueblo pone al servicio de este fin toda su creatividad e ingenio en la creación de apodos. Por cste motivo, algunas personas no aceptan de buen grado el apodo.

Las líneas generales en la creación de apodos, desde el punto de vista linguiístico podemos resumirlas en:

a) Derivados como Mota $>$ Moteños, Lillo $>$ Lillero, Murcia $>$ Murciana, patata $>$ Patatilla, tartana $>$ Tartanero, orejas $>$ Orejitas...

b) Compucstos, sobre todo los formados de 'verbo + sustantivo', como: Correnozas, Matachivos, Robamelones,... aunque también cncontramos algún caso de "sustantivo + (preposición) + sustantivo" 12 como en Culo(de)hierro.

c) Una falsa analogía en Mengañastes, en donde se observa que el hablante por analogía con la scgunda persona del singular, añade una $/ \mathrm{s} /$ al pronombre que por naturaleza es ya de segunda persona de singular.

d) Vulgarimos fonéticos los Perdios, los Coloraos...

c) Acortamicntos Buta(nero), Gigan(te), Figu(ra)...

i) Transformaciones morfológicas de género con cambio de morfema, incluso cn palabras que carecen de tal moción. Es bastante frecuente el cambio de género de femenino a masculino y de masculino a femenino, dependiendo de si la base que sirve de motivación es masculina y se aplica a un apodado de sexo femenino, y a la inversa (patata $>$ Patato, furriel $>$ Fuerriela).

g) Amalgamas, sobre todo las que se producen: adjetivo posesivo + base del apodo, Mistomates, Mitorres...

h) Scmánticamentc, abundan las exageraciones, las descripciones hiperbólicas de la realidad, las metáloras, las comparaciones,... es decir, la utilización de cualcquicr recurso que demuestre el ingenio y la gracia del creador; así encontramos, Culona, Camijo, Aguja, Palosecos, Gordo, Chiquitín (a pesar de medir cerca de 1,90), Gigante, el Jaro, Adoquín...

Este recorrido por los principales recursos de los que el apodo se sirve para presentarse formalmente, nos permiten determinar que nos encontramos ante un hecho puramente popular que manifiesta la lengua coloquial de un pueblo, que a su

\footnotetext{
Sobre este tipo de compuestos véase E. Coseriu, 1987: 239-264.
} 
vez pone en evidencia los usos y tendencias no recogidos por escrito, pero no por ello menos interesantes o difusores de los fenómenos internos de una comunidad linguiística.

\section{Conclusiones}

En cstas páginas se presenta un intento de sistematización y la ejemplificación de algunas de las cuestiones más atractivas que atañen al fenómeno del apodo. A través de un análisis de rasgos, historia, tradición, concepto, origen,... así como del resultado de las informaciones y entrevistas 'in situ' a personas conocedoras de toda la tradición del apodo villacañero, se configura un marco de estudio realmente interesante.

La demostración de que estamos ante una tradición popular heredada es evidente a lo largo de todo el trabajo. Analizados los rasgos que la caracterizan, observamos que nuestra tradición es una de las más arraigadas en la sociedad, que se ha mantenido a pesar del paso del tiempo. No obstante, son claras también las barreras expansivas a que se ve sometida en las últimas décadas, pues cada vez los apodos quedan más restringidos a comunidades de menor tamaño.

Nuestro objetivo es que este trabajo se interprete como un primer acercamiento al estudio del apodo, pues sabemos que es necesario un análisis detallado y comparativo del fenómeno, lo cual permitiría extraer interesantes conclusiones sobre las inclinaciones imperantes en una sociedad, conociendo desde otro punto de vista a sus habitantes, su geografía, su historia o su cultura.

En definitiva, ha resultado un trabajo apasionante en todas sus facetas, si bien hemos de destacar la parte empírica, en donde el estudio del fenómeno a través del mismo pueblo ha sido verdaderamente provechoso, pues hemos podido comprobar la riqueza e inmenso patrimonio cultural que poseemos.

\section{Referencias bibliográficas:}

Beinhauer, Werner (1991): El español coloquial (Prólogo de Dámaso Alonso. Traducción española de Fernando Huarte Morton), $3^{\mathrm{a}}$ ed. aumentada y actualizada, Madrid: Gredos.

Abad Hernán, Pedro-Pablo y Helguera Castro, $\mathrm{M}^{\mathrm{a}}$ Ángeles (1990): «Apodos en la ciudad de Dueñas (Palencia)», Revista de Folklore, Valladolid, Obra Cultural de Caja España, 117, págs. 87-92.

Ariza Viguera, Manuel (1982): Intento de bibliografía de la onomástica hispánica, Cáceres: Universidad de Extremadura. 
Ariza Viguera, Manuel (1993): «¿Es propio el nombre propio?» en Estudios lingiiústicos en torno a la palabra (Esperanza R. Alcaide, $\mathrm{M}^{\mathrm{a}}$ del Mar Ramos y Francisco J. Salguero, eds.), Sevilla: Universidad de Sevilla, págs. 33-40.

Bonachera Cano, Antonio M (1997): «Origen y esencia de los motes y apodos en el Albayzín. Mecanismos de creación y de herencia», en Teoría y práctica de la Lexicologia (IV Jornadas Internacionales sobre Estudio y Enseñanza del léxico), Granada: Universidad de Granada, págs. 141-146.

Castillo de Lucas, Antonio (1959): «Apodos y motes españoles (Ensayo de Antroponimia popular con vocabulario médico)» en Trabalhos de Antropologia e Etnologia, Oporto, Instituto de Antropologia, Facultade de Ciencias, vol. XVII, fasc. 14, págs. 371-380.

Cela, Camilo José (1966): Del Miño al Bidasoa. Notas de un vagabundaje, $4^{\mathrm{a}}$ ed., Barcelona-Madrid: Noguer.

Codera, Francisco (1909): «Apodos o sobrenombres de Moros españoles» en Mélanges Hartwig Derenblourg. Recueil de travaux d'érudition dédiés à la memoire d'Hartwig Derenbourg par ses amis et ses éléves, París: Ernest Leroux (cd), págs. 323-334.

Coscriu, Eugenio (1987): Gramática, Semántica, Universales, $2^{a}$ ed., Madrid: Gredos.

Chevalier, Maxime (1982): «El arte de motejar en la Corte de Carlos V» en Cuadernos de investigación de la literatura hispánica, Madrid: Fundación Universitaria Española Seminario «Menéndez Pelayo», $n^{\circ}$ 4, págs. 6I-77.

Deliî́n Val, José (1981): «Apodos, motes y cognomentos» en Revista de Folklore, Valladolid: Obra Cultural de la Caja de Ahorros Popular, n 3, págs. 3-13

Delibes, Migucl (1980): El camino, 24ª ed., Barcelona: Destino.

Díez Barrios, Germán (1995): Motes y apodos, Valladolid: Castilla ediciones.

Fernández Leborans $M^{a}$ Jesús (1999): «El nombre propio» en Gramática descriptiva de la lengua española (Ignacio Bosque y Violeta Demonte, eds.), Madrid: Espasa-Calpe, págs. 77-128.

Fernándcz Oxca, José Ramón (1971): «Mil y pico de apodos orensanos» en Revista de Dialectología y Tradiciones populares, Madrid: CSIC, tomo XXVII, cuadernos $3^{\circ}$ y $4^{\circ}$, págs. 345-369.

Gamito Jiménez, Juan Luis (1993): «Apodos estepeños» en Aproximación a la cultura popular de Estepa, Estepa: Ayuntamiento de Estepa, págs. 45-63.

García Gallarín, Consuelo (1999): El nombre propio. Estudios de historia linguiística española, Madrid: PATROM.

García Vergara, Gabriel (1947): «Apodos que aplican a los naturales de algunas localidades de la provincia de Guadalajara los habitantes de los pueblos próximos a ellas», Revista de Dialectología y Tradiciones populares, Madrid: CSIC, tomo III, cuaderno $1^{\circ}$, págs. 58-67. 
García Vergala, Gabriel (1950): «Apodos que aplican a los naturales de algunas localidades de la provincia de Burgos los habitantes de los pueblos próximos a elloss, Revista de Dialectologia y Tradiciones populares, Madrid: CSIC, tomo IV, cuaderno $4^{\circ}$, págs. 531-553.

Gómc Macker, Luis A. (1977): «El sobrenombre: implicaciones socioculturales» en Estudios filológicos, Valdivia: Universidad de Chile, $\mathrm{n}^{\circ}$ 12, págs. 97-109.

Iglesias Ovejero, Ángel (1980): «La función eponímica en la onomástica popular: los motes actuales en el Rebollar (Salamanca)», Español Actual, 37-38, págs. 722.

López García, Ángel (1985): «Lo propio del nombre propio», Lingüística Española Actuctl, vol. VII/1, págs. 37-54.

Moliner, María (1998): Diccionario del uso del español, $2^{a}$ ed., 2 tomos, Madrid: Credos.

Mori, Olga (1993): «Características personales sugeridas por el apodo», Anuario de Estudios Filológicos, XVI, págs. 101-112.

Ocaña Torrejón, Juan (1961): «Apodos de los naturales del Valle de los Pedroches», Boletín de la Real Academia de Córdoba de Ciencias, Bellas Letras y Nobles Artes, Córdoba: CSIC, 81, págs. 141-I48.

Oliarquina, Ricardo (1996): «Cambios en los nombres propios entre abuelos y niclos», Cuademos de Etnología y Etnografía de Navarra, Pamplona: Fondo de Publicaciones del Gobierno de Navarra, 68, págs. 237-251.

Paredes-Candia, Antonio (1977): El apodo en Bolivia, La Paz: Editorial Isla.

Pires de Lima, J.A. (1949): «Os moradores de S. Simão de Novias e suas alcunhas", Revista de Dialectología y Tradiciones populares, tomo V, cuaderno 3", págs. 353-357.

Real Academia Española (1992): Diccionario de la Lengua Española, $21^{\text {a }}$ ed., Madrid: Espasa-Calpe.

Rebollo Torío, Miguel A. (1988): «El apodo y sus características», Anales del instituto de Linguiística, Argentina: Universidad de Cuyo, XIV, págs. 343-350.

Salarar y Acha, Jaime de (1991): Génesis y evolución histórica del apellido en España, Madrid: Real Academia Matritense de Heráldica y Gcnealogía.

Sánchez. Aybar, Carmen (1987): «El apodo. Su manifestación en Tendilla», Cuademos de Etnología de Guadalajara, Guadalajara: Institución Provincial de Cultura «Marqués de Santillana», 21, págs. 7-35.

Seco, Manuel, Andrés, Olimpia y Ramos, Gabino (1999): Diccionario del español actucil, 2 tomos, Madrid: Aguilar.

Vila Nova, Alfredo da (1982): «Sobrenomes e alcuñas de Beluso (Bueu)», Museo de Pontevedra, Vigo, 36, págs. 436-442. 